\title{
Hydroxyphenylation of Histone Lysines: Post-translational Modification by Quinone Imines
}

\author{
Kodihalli C. Ravindra ${ }^{\ddagger}$, Laura J. Trudel ${ }^{\ddagger}$, John S. Wishnok ${ }^{\ddagger}$, Gerald N. Wogan ${ }^{\ddagger}$, Steven R. \\ Tannenbaum ${ }^{\ddagger}, \S$, and Paul L. Skipper $\neq, \AA$ \\ ‡Department of Biological Engineering, Massachusetts Institute of Technology, Cambridge, MA \\ §Department of Chemistry, Massachusetts Institute of Technology, Cambridge, MA
}

\begin{abstract}
Monocyclic aromatic amines are widespread environmental contaminants with multiple sources such as combustion products, pharmaceuticals, and pesticides. Their phenolic metabolites are converted intracellularly to electrophilic quinone imines upon autoxidation and can embed in the cellular matrix through a transimination reaction that leaves a redox-active residue as a substituent of lysine side-chain amino groups. To demonstrate the occurrence of this process within the cellular nucleus, Chinese hamster ovary AA8 cells were treated with the para-phenol of 3,5dimethylamine, after which the histone proteins were isolated, derivatized, and subjected to tryptic digestion. The resulting peptides were analyzed by tandem mass spectrometry to determine which lysines were modified. Nine residues in histones H2A, H2B, and H4 were identified; these were located in histone tails, close to where DNA makes contact with the nuclear core particle, elsewhere on the protein surface, and deep within the core. Kinetics of disappearance of the modified lysines in cultured cells was determined using isotope-dilution mass spectrometry. AA8 cells were also transfected with the genetically encoded hydrogen peroxide biosensor HyPer in constructs that lead to expression of HyPer in different cellular compartments. Challenging the resulting cells with the dimethylaminophenol resulted in sustained fluorescence emission in each of the compartments, demonstrating ongoing production of $\mathrm{H}_{2} \mathrm{O}_{2}$. The kinetics of modified lysine loss determined by mass spectrometry was consistent with persistence of HyPer fluorescence emission. We conclude that the para-phenol of 3,5-dimethylamine can become stably integrated into the histone proteins, which are minimally repaired if at all, and function as a persistent source of intracellular $\mathrm{H}_{2} \mathrm{O}_{2}$.
\end{abstract}

\section{Graphical Abstract}

\footnotetext{
"To whom correspondence should be addressed at Massachusetts Institute of Technology, 77 Massachusetts Ave., Building 56, Room 753, Cambridge, MA 02139. Tel.: 617-253-0983; Fax: 617-252-1787; skipper@ mit.edu.

Supporting Information. Schemes outlining synthesis and derivatization methods, sample analysis workflow, and molecular fragmentations. Figures showing chromatographic separations, calibration curves, and mass spectra.
} 


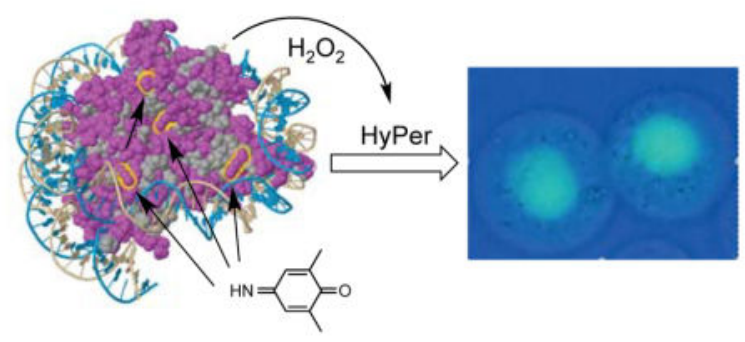

A principal oxidative metabolite of monocyclic aromatic amines is the $o$ - or $p$-phenol when these positions are not substituted. Phenolic products are typically further metabolized to yield conjugates that are unreactive and are eliminated by excretion. Aminophenols as such have nucleophilic rather than electrophilic character and are thus of little biological significance with respect to covalent modification of proteins. However, when not conjugated with sulfate or glucuronic acid they are subject to both autoxidation as well as enzymatically catalyzed oxidation to their quinone imine form, reversing the nucleophilicity of the aminophenolic molecule to electrophilicity. Notable examples of the consequences of this polarity inversion have been reported. ${ }^{1,2}$

Two distinctly different pathways are available for quinone imines to react with cellular nucleophiles, 1,4-addition — substitution of the quinone imine permitting-to give a Michael product with the substituent meta to either the imine or the carbonyl function, and 1,2addition to the imine to give a tetrahedral product that may be stable or may, depending on the nucleophile, eliminate $\mathrm{NH}_{3}$. Scheme 1 illustrates the various reaction pathways and possible products. In the case of ipso attack followed by $\mathrm{NH}_{3}$ elimination, when the nucleophile is a primary amine the product is an $N$-substituted quinone imine and the process is known as transimination. ${ }^{3,4}$ The product may in turn be reduced to its aminophenol oxidation state. As a leading example, we have reported ${ }^{5}$ that this overall reaction pathway occurs in vivo with 3,5-dimethylaminophenol (3,5-DMAP), which is readily oxidized to the quinone imine following administration and lysine residues probably located in histones, giving products that are quite stable in vivo. It has also been demonstrated that AA8 Chinese hamster ovary $(\mathrm{CHO})$ cells treated with 3,5-DMAP exhibit elevated levels of reactive oxygen species (ROS) for several days following exposure to and withdrawal of the compound. Presumably, the elevated levels of ROS result from redox cycling of the hydroxyphenyllysine residues formed by reaction of 3,5-

dimethyliminoquinone with various lysine residues, not all of which are necessarily in the histone proteins.

The prior studies cited above were initiated in an effort to clarify the mechanism(s) of mutagenic action attributable to 3,5-DMAP and related aminophenols, one of which that was considered possible was production of DNA-damaging levels of ROS. The observations that intracellular fluorescent dye is oxidized in DMAP-treated cells and that lysine transimination products are simultaneously present certainly support the hypothesis. In the present study we set out to confirm our initial inference, based on identification of monomeric $N^{e}$-(3,5-dimethyl-4-hydroxyphenyl)-lysine (DMHPL), that lysine residues within the histones are hydroxyphenylated in the intracellular transimination of 3,5-DMAP. 
In addition, we wished to prove, using cultured cells which had been transfected with HyPer constructs which incorporate a fluorescent $\mathrm{H}_{2} \mathrm{O}_{2}$ reporter gene, ${ }^{6-8}$ that hydrogen peroxide is among the oxidants produced since $\mathrm{H}_{2} \mathrm{O}_{2}$ is known to be cause mutagenic changes in DNA. Further objectives were to demonstrate that ROS generated within cells treated with 3,5DMAP can be found in the nucleus itself and that ROS and histone DMHPLs are present simultaneously.

\section{Results and Discussion}

Localization of intracellular dimethylhydroxyphenyllysine (DMHPL) within histones: Identification of monomeric DMHPL isolated from nuclear histone preparations, reported previously, 5 indicated that one or more lysine residues within the histone proteins react with 3,5-DMAP when cultured AA8 cells are treated with this aminophenol. This conclusion depends on the assumption that no minor component of the histone preparation was the actual contributor of the extracted DMHPL. ${ }^{14} \mathrm{C}$-tracer studies ${ }^{5}$ further suggested participation by each of the histones $\mathrm{H} 2 \mathrm{~A}, \mathrm{H} 2 \mathrm{~B}, \mathrm{H} 3$, and $\mathrm{H} 4$. Tracer studies are useful for detecting products irrespective of their identity but, unlike mass spectrometric methods, are uninformative regarding chemical structure. To overcome these limitations and provide a firm proof that DMHPL is formed by histone lysine residues, we undertook the identification of specific lysines within the polypeptide chains of the several histones by mass spectrometric analysis of tryptic peptides modified by hydroxyphenyl substitution at the $N^{\varepsilon}$-amino group. The requisite histones were obtained as isolates from non-transfected AA8 cells treated with 3,5-DMAP.

Efforts were initially undertaken to identify hydroxyphenylated peptides by HPLC-MS/MS analysis of tryptic digests of purified histones isolated from 3,5-DMAP treated cells. In this approach, mass spectra were examined for the presence of molecular ions corresponding to those calculated for unmodified tryptic peptides with an increase of $120 \mathrm{Da}$, corresponding to substitution of a hydrogen atom by a dimethylhydroxyphenyl group. When such ions were observed, product ion spectra were analyzed for the presence of appropriate $y$ and $b$ ions. This approach failed to give convincing evidence for presence of the lysine modification. Possible reasons for the lack of success include the fact that aminophenols are subject to oxidation throughout the entire process, creating ambiguity regarding molecular weight. Oxidation would also be expected to lead to degradation of analytes. We consequently adopted an alternate strategy based on derivatization of the presumed adducts with 2dimethylaminoethanethiol (DMET) as outlined in Scheme S1 in the Supporting Information. This compound has a Michael-reactive nucleophilic group for reaction with the quinone imine form of DMHPL. As observed in preliminary experiments with synthetic DMHPL, the Michael product with a thiol reagent has greatly reduced susceptibility to oxidation. DMET also has a strongly basic tertiary amino group to provide a preferential site for charge formation in the mass spectrometer. Previous studies have shown that this reagent can enhance separation of small tryptic peptides, ${ }^{9}$ improves the ionization of carcinogenadducted peptides, and yields a set of characteristic diagnostic fragment ions. ${ }^{10}$ Lastly, the DMET structure does not introduce ions of the same mass as those produced by peptide fragments. 
To assess this derivatization strategy, the peptide SKDP (with the $N$-terminal amino group acetylated) was reacted with 3,5-DMAP and the product then reacted with DMET. A high resolution MS/MS spectrum of the final product is shown in Figure 1 (see also Figure S1 in the Supporting Information). The protonated molecular ion is at $\mathrm{m} / \mathrm{z} 711.3398$. The major signals in the low-energy $(25 \mathrm{eV}$ ) product ion spectrum from $\mathrm{m} / \mathrm{z} 711.3398$ (data not shown) are at $\mathrm{m} / \mathrm{z} 606.2781$ and $\mathrm{m} / \mathrm{z} 104.0528$. MS/MS spectra at $40 \mathrm{eV}$ collision energy (e.g., Figure 1) additionally show the characteristic features of the DMET group $(\mathrm{m} / z$ 58.0651, 72.0808 , and 104.0528) and the ion at $m / z 84.0808$ corresponds to $\mathrm{C}_{5} \mathrm{H}_{10} \mathrm{~N}^{+}$, a characteristic of lysine-containing peptides. ${ }^{11-13}$ The ion at $\mathrm{m} / \mathrm{z} 606.2781$ derives from the neutral loss of 105.0612, a mass equal to that of DMET. Formally, this fragmentation corresponds to a reversal of the Michael reaction that formed the derivatized, DMHPL-modified peptide but the mechanism is likely different. (In the CID spectra of the various identified peptides isolated from histones-Figures S5-S7—neutral loss of 103, also corresponding to a DMET fragment was observed approximately as often as loss of 105. A detailed analysis of this fragmentation as well as that which produces the 104 fragment ion is given there in Scheme S2.) The universe of potential SKDP-derived fragment ions does not include $m / z$ 104.0528. Signals at $m / z 58.0651$ and $m / z 72.0808$ represent sequential trigger-ion fragments from the sulfur-containing probe.

These observations led to the following overall strategy for derivatized, hydroxyphenylated peptide identification: HPLC-MS/MS product-ion analysis was performed on tryptic digests of purified histones. From the collected data, molecular ions were identified that produced the diagnostic fragment ion at $\mathrm{m} / \mathrm{z}$ 104.0534. Agilent Masshunter Workstation and BioConfirm software - customized for identification of peptides modified by reaction of any lysyl residues with 3,5-DMAP followed by reaction with DMET — were then applied to nominate structures for confirmation. Subsequent targeted HPLC-MS/MS analysis was then conducted to acquire product ion spectra suitable for sequencing after confirmation that the diagnostic ions $m / z 58,72,84$, and 104 were present. The strategy and workflow are shown in Scheme S3.

Sequences of the identified peptides are given in Table 1, which also indicates the originating histone, specific reacting lysine residue, and general location of the targeted lysines within the octameric structure. CID mass spectra of the identified peptides are given in the Supporting Information. Precise location of the lysine residues that occur within the nucleosome core particle (NCP) was determined by reference to the crystallographic structure of the human NCP (PDB 2cv5) since there are no structure determinations reported for hamster NCPs. Nevertheless, the human NCP structure should be a suitable structure, since human and hampster sequences differ by only two amino acids: in the latter a serine substitutes for cysteine in $\mathrm{H} 3$ and for alanine in $\mathrm{H} 2 \mathrm{~B}$. As previously noted, ${ }^{14}$ substantially greater sequence divergence does not lead to gross structural differences.

The lysine residues indicated in Table 1 are situated throughout the histone octamer. Lys5 in $\mathrm{H} 2 \mathrm{~B}$, lys 4 and lys 23 in $\mathrm{H} 3$, and lys 8 and lys 12 in $\mathrm{H} 4$ are found in the $\mathrm{N}$-terminal tails and do not appear in the crystal structure. As shown in Figure 2, lys36 and lys118 in H2A, lys85 in $\mathrm{H} 2 \mathrm{~B}$, and lys 31 in $\mathrm{H} 4$ are all in the region where DNA is in contact with the histone octamer and their $N$-epsilon amino groups appear to be directed toward the double helix. Lys95 in 
$\mathrm{H} 2 \mathrm{~A}$ resides below the surface at the central axis of the $\mathrm{NCP}$ and its amino group appears to be directed inward rather than toward the surface. Lys 108 in H2B is similarly near the central axis but on the surface with its amino group readily accessible.

Quantitation of dimethylhydroxyphenyllsine (DMHPL) residues in histones by mass spectrometry: An isotope-dilution mass spectrometric method for quantitating DMHPL was developed to address the goal of determining the time-dependence of this histone modification in cells treated with 3,5-DMAP. Quantitation of each specific modified tryptic peptide identified above was considered outside the scope of this project as each would require its own internal standard (IS) and because the levels of each were likely to be too low for accurate quantitation. The required IS for DMHPL was obtained as shown in Scheme S4 by reaction of 3,5-DMAP with isotopically labelled lysine in which all carbon six atoms were ${ }^{13} \mathrm{C}$ and both nitrogens were ${ }^{15} \mathrm{~N}$ giving a mass difference of eight $\mathrm{Da}$.

CID-MS analysis of isotopic DMHPL revealed two major fragment ions corresponding to those observed in the spectrum of the isotopically normal molecule (Figures S2 and S3). Comparison of the two spectra confirms the tentative structure assignments for the fragments made previously. ${ }^{5}$ In each case, scission of the lysine moiety's epsilon carbonnitrogen bond with loss of the DMAP moiety as a neutral gives the fragment ions at 130 (267 - 137) and 137 (275 - 138) amu from the analyte and IS, respectively. Here, the neutrals differ by one amu because the DMAP moiety of the IS includes an ${ }^{15} \mathrm{~N}$ atom contributed by lysine through transimination. The smaller fragment ions at 84 and 90 arise from further loss of $\mathrm{CH}_{2} \mathrm{O}_{2}$, and differ by six mass units rather than seven because the ion derived from the IS retains only six of the eight original isotopically labelled atoms.

Quantitation of DMHPL was performed using MRM for the transitions $275.2 \rightarrow 90.1$ (IS) and $267.2 \rightarrow 84.1$ (analyte). The calibration curve (Figure S4) based on $100 \mathrm{fmol}$ of IS was linear over the range 10 to $2000 \mathrm{fmol}$ where $10 \mathrm{fmol}(2.66 \mathrm{pg})$ was the limit of detection. Samples of histones for MS analysis were obtained from non-transfected cells that had been exposed to $25 \mu \mathrm{M} 3,5$-DMAP for up to $24 \mathrm{~h}$. The briefest exposure was achieved by washing cells immediately after exposure and is indicated as $0 \mathrm{~h}$ in Figure 3. The $0 \mathrm{~h}$ timepoint represents the minimal possible exposure under the experimental protocol used, which is approximately two minutes. The other exposure times can be considered as true values. DMHPL was undetectable in cells not exposed to 3,5-DMAP.

Production of $\mathrm{H}_{2} \mathrm{O}_{2}$ in HyPer-transfected cells: Fluorescence detection in the present study was performed using cells transfected with a fluorescent reporter gene, both to avoid confounding by processes that can generate fluorescence from exogenous dyes and to reveal intracellular localization of fluorescent signal. The latter objective was addressed by transfecting Chinese hamster ovary AA8 cells with HyPer constructs that target the nucleus, mitochondria or cytosol. In each case, cell lines were established in which most, if not all, individual cells exhibited a notable increase in fluorescence when challenged with $100 \mu \mathrm{M}$ $\mathrm{H}_{2} \mathrm{O}_{2}$. As expected, fluorescence was confined to the cellular compartment in which the HyPer construct is expressed. Confocal microscopy images of each cell type (nucl, mito, cyto) are given in Figure 4. 
In all three cell types signal produced by exogenous $\mathrm{H}_{2} \mathrm{O}_{2}$ peaked rapidly and decayed in well under the two hour time frame used for fluorescence measurements as shown in Figure 5. Fluorescence of mito and cyto cells reached a baseline, which was lower than pretreatment levels, by twenty minutes after the peak at five minutes. Nucl cells required approximately twice as long to reach their baseline, which was indistinguishable from pretreatment levels. Similarly, when challenged with $25 \mu \mathrm{M}$ 3,5-DMAP all three cell types exhibited maximal fluorescence at the earliest timepoint, five minutes. In contrast, fluorescence declined only marginally and remained elevated for the two hour duration of the experiments.

Additional kinetic experiments were performed in which cells were first exposed to $25 \mu \mathrm{M}$ 3,5-DMAP for one hour, then washed to remove any unreacted or otherwise extractable products of the aminophenol. Fluorescence was then measured over a further two hour period. This procedure was repeated with addition of ascorbate present in the wash medium and subsequently during fluorescence measurement. Results are shown in Figure 6. In the absence of ascorbate, it is apparent that there was no significant change in fluorescence emission, which was elevated relative to untreated cells, by any of the three cell types over the two hours of the experiment. Nucl cells exhibited the highest fluorescence emission in the absence of ascorbate. In the presence of ascorbate, fluorescence emission was depressed in all three cell types to below those levels observed in untreated cells. This result is not unexpected given that there are endogenous sources of $\mathrm{H}_{2} \mathrm{O}_{2}$. Fluorescence emission in nucl cells was much less depressed than in the other two cell types and most depressed in the mito cells. This order is consistent with the presumptions that endogenous $\mathrm{H}_{2} \mathrm{O}_{2}$ originates mostly in the mitochondria and that the nucleus is least exposed to it.

Results given here demonstrate that lyine residues in the histone proteins undergo a transimination reaction with 3,5-DMAP to yield stable dimethylhydroxyphenyl derivatives. Previous experiments ${ }^{5}$ were limited to detecting monomeric DMHPL so contamination with other nuclear proteins could not be ruled out. In the present work, we isolated DMHPLcontaining peptides with sequences specific to those found in the longer histone polypeptides. Nine different lysines in three of the four core histones (H2A, H2B, and H4) were identified as reacting with 3,5-DMAP to form a DMHPL adduct. Two lysines in the tail of histone $\mathrm{H} 3$ were also possibly targeted by 3,5-DMAP, though the evidence is less satisfactory. The broad range of binding sites observed suggests that multiple reaction mechanisms with different degrees of kinetic or thermodynamic control are involved and might be expected since the reaction takes place with the quinone imine form and is thus a condensation reaction, which is in principle reversible until the ring re-aromatizes, but the reaction is between a small molecule and a protein and thus not readily described by ordinary small molecule reaction kinetics.

Irrespective of the reaction mechanism(s) involved, formation of DMHPL occurs in the time frame of minutes as judged from the data given in Figure 4. Peak DMHPL levels were observed at around two hours but levels at the $0 \mathrm{~h}$ timepoint were already about $40 \%$ of peak. The $0 \mathrm{~h}$ timepoint does not represent true zero exposure; it represents exposure for about two minutes before the cells could be effectively washed with medium containing ascorbate, which effectively blocks further reactivity of free 3,5-DMAP by converting it the 
aminophenol. Levels declined by somewhat over $50 \%$ from two to $24 \mathrm{~h}$ to a level well above the limit of detection. These results are consistent with previous studies using dichlorofluorescein as the reporter that indicated persistent levels of DMHPL $24 \mathrm{~h}$ after exposure as well as several days later.

The temporal profile of DMHPL levels in histones of non-transfected AA8 cells is consistent with observations of fluorescence emission by nucl-HyPer transfected cells although neither set of fluorescence data (Figure 5, Figure 6) is strictly comparable with the MS data of Figure 3 because the treatment protocols differed. In the former experiments with nucl HyPer cells, exposure to 3,5-DMAP was continued throughout the fluorescence measurement period; in the latter there was a one hour exposure period followed by washout of residual 3,5-DMAP and its extractable successor products prior to two hours of fluorescence measurement. For DMHPL determinations, the duration of exposure equalled the elapsed time until cells were harvested for analysis. However, it is apparent that both protocols for fluorescence measurement produced essentially the same result: little change over the two hours following initiation of exposure in one case and three hours in the other. Likewise, DMHPL levels exhibited little variation from one to four hours. The closest points of comparison are the initial values of DMHPL and fluorescence in the case of continuous exposure (Figure 5). Here the data are divergent, DMHPL being lower than at later time points and fluorescence being higher. The difference, though, is predictable and likely reflects the fact that a certain amount of time is required for 3,5-DMAP to react with the protein while free 3,5-DMAP is immediately redox active but degrades with time under aerobic conditions.

Finally, we consider the question of whether a fluorescent response of HyPer expressed in one cellular compartment can be considered as evidence that $\mathrm{H}_{2} \mathrm{O}_{2}$ is generated in that compartment. The fluorescent response of nucl cells when exposed to 3,5-DMAP is prima facia evidence that the nucleus experiences increased levels of $\mathrm{H}_{2} \mathrm{O}_{2}$ as a result. We have previously put forth the hypothesis that DMHPL in histones may be a highly localizedwith respect to DNA—source of $\mathrm{H}_{2} \mathrm{O}_{2}$ and therefore one of considerable significance for oxidative damage to the genome. This hypothesis is not tested by the present results unless it can be concluded that the fluorescent response of nucl cells is attributable primarily to generation of $\mathrm{H}_{2} \mathrm{O}_{2}$ within the nucleus but it is not clear how one can reach that conclusion. Therefore, although it is apparent that DNA is exposed to elevated levels of $\mathrm{H}_{2} \mathrm{O}_{2}$ when cells are exposed to 3,5-DMAP, the relative contribution from histone DMHPLs remains indeterminate. What can be assumed, however, is that it will be among the most persistent because histones are structural proteins with little turnover and, as we have shown (Ozbal), chemically stable small molecule modifications of histones are preserved during cell replication. ${ }^{15}$

\section{Methods}

\section{Chemicals and reagents}

3,5-DMAP (This nomenclature differs from the IUPAC system for the purpose of preserving the numbering used for the amines from which the aminophenols and quinone imines are derived) was synthesized by catalytic reduction of 2,6-dimethyl-4-nitrosophenol using 10\% 
$\mathrm{Pd} / \mathrm{C}$ in dry $\mathrm{CH}_{3} \mathrm{OH}$ at room temperature and atmospheric pressure for $2 \mathrm{~h}$. After filtration of the reaction mixture through Celite the product was obtained in $97 \%$ yield by evaporation of solvent. It was identical by TLC and LC/MS with the product obtained previously through an alternate route. ${ }^{5}$

Ammonium bicarbonate (CAS: 1066-33-7), Urea (CAS: 57-13-6), HPLC, LC/MS solvents and Eagle's minimum essential medium (MEM, Cat. No. M4526) were purchased from Sigma-Aldrich (St. Louis, MO). Dimethylaminoethanethiol (DMET) hydrochloride was purchased from Fisher Scientific (Cat No. AC115810050). Vivaspin 3k MW cut-off centrifuge filters were purchased from Sartorius Stedim Biotech (Goettingen, Germany). Sequencing grade modified trypsin (Cat. No. V5111) and ProteaseMAX ${ }^{\mathrm{TM}}$ surfactant, trypsin enhancer (Cat. No. V2071) were from Promega (Madison, WI). Synthetic peptide Thymosin b4 (1-4) (Cat. No. 885-21) was purchased from California Peptide Research Inc.

\section{AA8 cells and DMHPL analysis}

Chinese hamster ovary (CHO) AA8 cells were obtained from the American Type Culture Collection (ATCC, Rockville, MD). Cells were grown in MEM w/o ribonucleosides and deoxyribonucleosides supplemented with $10 \%$ fetal bovine serum (FBS, Atlanta Biologicals), $100 \mu \mathrm{g} / \mathrm{mL}$ L-glutamine, 100 units/mL penicillin-streptomycin (pen-strep, Lonza, Walkersville, $\mathrm{MD}$ ) in a humidified $5 \% \mathrm{CO}_{2}$ atmosphere at $37^{\circ} \mathrm{C}$. Cells were subcultured when confluence reached approximately $80-90 \%$.

To obtain histones with DMHPL modifications for the purpose of identifying 3,5-DMAP binding sites, AA8 cells were exposed to the compound as follows: Twenty-four hours prior to dosing, cells were plated at $5 \times 10^{6}$ cells/100mm tissue culture dish in Ham's F12 medium without ascorbate (Lonza) supplemented with $10 \% \mathrm{FBS}, 100 \mu \mathrm{g} / \mathrm{mL}$ L-glutamine and 100 units $/ \mathrm{mL}$ pen-strep. Immediately before dosing, plates were washed two times with $5 \mathrm{~mL}$ serum free Ham's (SF Ham's) supplemented with 100 units/mL pen-strep. After washing, $10 \mathrm{~mL}$ SF Ham's containing $25 \mu \mathrm{M}$ 3,5-DMAP in DMSO $(10 \mu \mathrm{L})$ or DMSO only was added and cells were incubated for $1 \mathrm{~h}$ at $37^{\circ} \mathrm{C}$. After $1 \mathrm{~h}$ medium was aspirated and the cells were washed once with $5 \mathrm{~mL}$ PBS containing $50 \mathrm{mg} / \mathrm{L}$ ascorbate (PBSA). Cells were scraped from the plates, pooled to provide $\sim 10^{7}$ cells/sample and resuspended in $10 \mathrm{~mL}$ PBSA. The cells were centrifuged at $4{ }^{\circ} \mathrm{C}, 1500 \mathrm{rpm}$; supernatant was aspirated and cell pellets were frozen at $-80^{\circ} \mathrm{C}$.

For quantitation of DMHPL by mass spectrometry, confluent AA8 cells grown in $150 \mathrm{~mm}$ dishes were treated for periods of $0,1,2,4,8$, and $24 \mathrm{~h}$ with $25 \mu \mathrm{M}$ 3,5-DMAP in SF Ham's after first being rinsed with pure SF Ham's. At the end of each treatment period, medium was aspirated and the cells were collected from the dishes as described above. Three dishes were used for each timepoint and the collected cells from each dish were kept in isolation.

Isolation of histones was performed by the acid extraction method described in complete detail in reference 16 . When required for binding site identification, isolated histones were taken up in $100 \mathrm{mM} \mathrm{pH} 8.0$ ammonium bicarbonate buffer containing 0.1\% SDS and incubated at $37{ }^{\circ} \mathrm{C}$ for $1 \mathrm{~h}$ prior to derivatization, which was achieved by adding $5 \mathrm{mM}$ DMET and incubating at $37^{\circ} \mathrm{C}$ for an additional $2 \mathrm{~h}$. Unreacted DMET was removed by 
ultrafiltration with a $3 \mathrm{k}$ cut-off filter. Derivatized histones were separated by HPLC using UV detection as described by earlier ${ }^{17}$ (see Figure S8) Purified histone fractions were lyophilized and trypsinized using sequence grade trypsin (1:27) from Promega. The surfactant ProMAX ${ }^{\mathrm{TM}}$ was used as trypsin enhancer during proteolysis according to manufacturer's instruction. The tryptic peptides were desalted using ZipTip C18 prior to mass spectrometric analysis.

For quantitative analysis of DMHPL content, TCA-precipitated histone protein was used without further fractionation. Total protein from each preparation was dissolved in $50 \mu \mathrm{L}$ of $100 \mathrm{mM}$ ammonium bicarbonate buffer $(\mathrm{pH}$ 8.0) and quantified using Bio-Rad protein estimation kit. The internal standard $\left[{ }^{15} \mathrm{~N}_{2}\right]\left[{ }^{13} \mathrm{C}_{6}\right]$-DMHPL (5 pmol) was added and the protein was digested with Streptomyces griseus protease (1 $\mathrm{mg}$ enzyme $/ 5 \mathrm{mg}$ protein) at $37^{\circ} \mathrm{C}$ for $6 \mathrm{~h}$. Samples were then dried under vacuum and re-suspended in $50 \mathrm{~mL}$ of water containing $1 \% \mathrm{CH}_{3} \mathrm{CN}$ before mass spectrometric analysis.

\section{Mass spectrometry}

Tryptic histone peptides were separated by ultra high-pressure liquid chromatography (UHPLC) using an Agilent 1290 LC system and an Agilent Extend-C18 (1.8 $\mu \mathrm{m}$, $2.1 \times 50 \mathrm{~mm}$ ) column (Agilent Technologies Palo Alto, CA) with a flow rate of $0.4 \mathrm{~mL} / \mathrm{min}$. Solvent A was $0.1 \%$ formic acid in water, and solvent $\mathrm{B}$ was $0.1 \%$ formic acid in acetonitrile $\left(\mathrm{CH}_{3} \mathrm{CN}\right)$. A linear gradient was performed as follows: $2 \% \mathrm{~B}$ at $0 \mathrm{~min}, 2 \% \mathrm{~B}$ at $1 \mathrm{~min}, 50 \%$ $\mathrm{B}$ at $9 \mathrm{~min}, 95 \% \mathrm{~B}$ at $13 \mathrm{~min}, 95 \%$ at $15 \mathrm{~min}, 2 \% \mathrm{~B}$ at $15.2 \mathrm{~min}$, and $2 \%$ at $18 \mathrm{~min}$. The following instrument and LC parameters were used for both auto MS/MS and targeted MS/MS experiments. The UHPLC was coupled to an Agilent 6530 quadrupole time-offlight (QTOF) (Agilent Palo Alto, CA) mass spectrometer equipped with an electrospray ionization (ESI) Jet stream source. Mass spectra were acquired in the $3200 \mathrm{Da}$ extended dynamic range mode $(2 \mathrm{GHz}$ ) using the following settings: ESI capillary voltage, $3800 \mathrm{~V}$; fragmentor, $160 \mathrm{~V}$; nebulizer gas, $30 \mathrm{psig}$; drying gas, $8 \mathrm{~L} / \mathrm{min}$; drying temperature, $380{ }^{\circ} \mathrm{C}$. Data were acquired at $6 \mathrm{MS}$ spectra per second and $3 \mathrm{MS} / \mathrm{MS}$ spectra per second in the mass ranges of m/z 100-2000 for MS, and 50-2500 for MS/MS and stored in profile mode with a maximum of five precursors per cycle. Fragmentation energy was applied at a slope of 3.5 V/100 Da with a 3.0 offset. Mass accuracy was maintained by continually sprayed internal reference ions, $\mathrm{m} / \mathrm{z} 121.0509$ and 922.0098 in positive mode.

For the identification of specific sites of DMAP adducts on the histone peptides, the data was extracted and processed with the BioConfirm workflow in the Agilent Masshunter software. In brief, the databases of individual histones were created in BioConfirm software using Chinese hamster histone sequences from Uniprot (H2A: G3HDU4, H2B: G3HDT7, H3: G3HDS5, and H4: G3H2T6). The data files were extracted using the Molecular Feature Extraction function in Mass Hunter and matched with these databases including the variable modifications to get the percentage coverage of the proteins. During searching, the following parameters were applied: trypsin as digesting enzyme, maximum of 2 missed cleavages, precursor mass tolerance $\pm 20 \mathrm{ppm}$, product mass tolerance $\pm 50 \mathrm{ppm}$, and maximum ambiguous precursor charge $=3$. Sequence coverage was $>90 \%$ in all cases. Next, the extracted data for each histone was matched against derivatized DMAP $\left(\mathrm{C}_{12} \mathrm{H}_{18} \mathrm{NOS}\right.$, 
+224.1109 ) as a customized modification to obtain the initial hits. Because of the plethora of post-translational histone modifications and to minimize false positive identifications, the data sets were searched against acetylation, SUMOlyation, ubiquitination, methylation (mono, di, tri), and phosphorylation. Finally the data sets were matched against underivatized DMAP $\left(\mathrm{C}_{8} \mathrm{H}_{9} \mathrm{O},+121.0653\right)$ to confirm the derivatization efficiency. Spectra of interest were manually inspected for all the modified and unmodified peptides. After the initial confirmation of the presence of derivatized DMAP adducts on the lysine containing peptides, the samples were analyzed by targeted MS/MS to get diagnostic fragment ions and for further confirmation.

An Agilent 1200 capillary HPLC system interfaced to an Agilent Triple Quad LC/MS (model 6430) was used for quantitative analysis by MRM of DMHPL. Chromatography was performed with a Phenomenex Luna reverse phase C18 column $(150 \mathrm{~mm} \times 1.00 \mathrm{~mm}, 5 \mu \mathrm{m})$ eluted with a gradient of $0.1 \%$ formic acid in water (buffer A) and acetonitrile (buffer B) at $20 \mu \mathrm{L} / \mathrm{min}$. The solvent composition was ramped from $1 \% \mathrm{~B}$ at $0 \mathrm{~min}$ to $25 \%$ over $12 \mathrm{~min}$, followed by a linear increase to $98 \% \mathrm{~B}$ from 12 to $20 \mathrm{~min}$, and returned to $1 \% \mathrm{~B}$ at $23 \mathrm{~min}$.

The mass spectrometer parameters were: ESI capillary voltage, $3500 \mathrm{~V}$; gas temperature, $340{ }^{\circ} \mathrm{C}$; drying gas flow, $10 \mathrm{~L} / \mathrm{min}$; and nebulizer pressure, 40 psi. For the transitions 267.2 $\rightarrow 130.1$ and $275.2 \rightarrow 137.1$ (analyte and IS, resp.), the fragmentor voltage was set to 100 and collision energy to 18 . For the transitions $267.2 \rightarrow 84.1$ and $275.2 \rightarrow 90.1$, the respective parameters were 100 and 23. For precursor ion and high resolution mass spectrometric analyses used to select these parameters as well as determine the identities of the fragments see Figures S2 and S3.

A calibration curve for the analyte was constructed over the range of 10 - $2000 \mathrm{fM}$ DMHPL and a constant concentration of $100 \mathrm{fM}\left[{ }^{15} \mathrm{~N}_{2}\right]\left[{ }^{13} \mathrm{C}_{6}\right]$-DMHPL. By using LC-MS/MS peak area ratios corresponding to analyte and internal standard the regression analysis of the relative response ratio was calculated. Calculations were based on the peak areas in the MRM chromatograms to yield the ratio of analyte $(\mathrm{m} / \mathrm{z}=267.2 \rightarrow 84.1)$ to internal standard $(\mathrm{m} / \mathrm{z}=275.2 \rightarrow 90.1)$; (relative response ratio) by plotting against their corresponding concentration ratios (Figure S4). Response was linear over the entire concentration range.

\section{HyPer cells and fluorescence analysis}

CHO AA8 were transfected with plasmids from Evrogen (Moscow, Russia) containing HyPer constructs targeted to cytosol (pHyPer-cyto, FP941), mitochondria (pHyPer-dMito, FP942), and nucleus (pHyPer-nuc, FP944). Transfection was performed using Lipofectamine 3000 (Invitrogen) according to the manufacturer's instructions. Stably transfected cells were selected on the basis of neomycin resistance using G418 (Geneticin). Further selection of expanded clones was made on the basis of fluorescent response when cells were challenged with $100 \mu \mathrm{M} \mathrm{H}_{2} \mathrm{O}_{2} \cdot{ }^{18}$

Fluorescence measurements for kinetics experiments were made using a Cellomics ArrayScan VTI HCS fluorescence plate reader (Thermo Scientific, CA, USA) with live cell imaging chamber $\left(37^{\circ} \mathrm{C}\right.$ and $\left.5 \% \mathrm{CO}_{2}\right)$. Ratiometric fluorescence emission was recorded at $535 \mathrm{~nm}$ with a $530 \mathrm{~nm}$ cutoff filter using $420 \mathrm{~nm}$ and $500 \mathrm{~nm}$ excitation filters. Fluorescence 
intensities were calculated using image $\mathrm{J}$ according to a previously published protocol. ${ }^{19}$ Each cell culture plate was analyzed once using an image comprising a minimum of one hundred cells.

Two experimental protocols were adopted to assess, respectively, the immediate response of HyPer-transfected cells to oxidant- or pro-oxidant exposure, or the modulation of response of presumptive DMHPL by ascorbate. In the first, cells were seeded into 96 well plates $(10,000 /$ well in $100 \mu \mathrm{L})$ in Ham's F-12 medium containing 10\% FBS. After $24 \mathrm{~h}$, the medium was aspirated and replaced with IMDM (serum free) without phenol red. Nuclei were stained with Hoechst 33342 and, after a $30 \mathrm{~min}$ incubation at $37^{\circ} \mathrm{C}$, cells were dosed with $50 \mu \mathrm{M} 3,5$-DMAP, in $50 \mu \mathrm{l}$ of IMDM to a final concentration of $25 \mu \mathrm{M}$. Fluorescence measurements were begun after approximately $5 \mathrm{~min}$ and then at $20 \mathrm{~min}$ intervals for $2 \mathrm{~h}$.

In the second, cells were grown in 96 well plates as above. After $24 \mathrm{~h}$, cells were washed with serum free Ham's and exposed to $25 \mu \mathrm{M}$ 3,5-DMAP in serum free IMDM for $1 \mathrm{~h}$. Medium was then removed and nuclei were stained for 10 minutes with Hoechst 33342 at the final concentration of $1 \mu \mathrm{g} / \mathrm{mL}$ in $50 \mu \mathrm{L}$ 10\% FBS IMDM. After 10 minutes another 50 $\mu \mathrm{L}$ of $10 \%$ FBS IMDM with or without ascorbate was added. Fluorescence was then recorded over a $2 \mathrm{~h}$ period as described above.

\section{Supplementary Material}

Refer to Web version on PubMed Central for supplementary material.

\section{Acknowledgments}

We thank Prof. Thomas Michel for the generous gift of the HyPer constructs. This work was supported by National Institutes of Health Grants PO1-ES006052 and P30-ES002109.

\section{References}

1. Jefferies PR, Quistad GB, Casida JE. Dialkylquinonimines validated as in vivo metabolites of alachlor, acetochlor, and metolachlor herbicides in rats. Chem Res Toxicol. 1998; 11:353-9. [PubMed: 9548806]

2. Martinez-Cabot A, Morato A, Messeguer A. Synthesis and stability studies of the glutathione and $\mathrm{N}$-acetylcysteine adducts of an iminoquinone reactive intermediate generated in the biotransformation of 3-(N-phenylamino)propane-1,2-diol: implications for toxic oil syndrome. Chem Res Toxicol. 2005; 18:1721-8. [PubMed: 16300381]

3. Yang QZ, Siri O, Braunstein P. Tunable N-substitution in zwitterionic benzoquinonemonoimine derivatives: metal coordination, tandemlike synthesis of zwitterionic metal complexes, and supramolecular structures. Chemistry. 2005; 11:7237-46. [PubMed: 16196074]

4. Lee Y, Sayre L. Model Reactions for the Quinone-Containing Copper Amine Oxidases. Anaerobic Reaction Pathways and Catalytic Aerobic Deamination of Activated Amines in Buffered Aqueous Acetonitrile. J Am Chem Soc. 1995; 117:3096-3105.

5. Ye W, Seneviratne UI, Chao MW, Ravindra KC, Wogan GN, Tannenbaum SR, Skipper PL. Transimination of quinone imines: A mechanism for embedding exogenous redox activity into the nucleosome. Chem Res Toxicol. 2012; 25:2627-2629. [PubMed: 23194336]

6. Belousov V, Fradkov A. Genetically encoded fluorescent indicator for intracellular hydrogen peroxide. Nat .... 2006; 3:281-286.

7. Malinouski M, Zhou Y, Belousov VV, Hatfield DL, Gladyshev VN. Hydrogen peroxide probes directed to different cellular compartments. PLoS One. 2011; 6:e14564. [PubMed: 21283738] 
8. Kalwa H, Sartoretto JL, Martinelli R, Romero N, Steinhorn BS, Tao M, Ozaki CK, Carman CV, Michel T. Central role for hydrogen peroxide in P2Y1 ADP receptor-mediated cellular responses in vascular endothelium. Proc Natl Acad Sci U S A. 2014; 111:3383-8. [PubMed: 24550450]

9. Steen H. A New Derivatization Strategy for the Analysis of Phosphopeptides by Precursor Ion Scanning in Positive Ion Mode. J Am Soc Mass Spectrom. 2002

10. Annan RS, Carr SA. The essential role of mass spectrometry in characterizing protein structure: mapping posttranslational modifications. J Protein Chem. 1997; 16:391-402. [PubMed: 9246619]

11. Couttas, Ta, Raftery, MJ., Bernardini, G., Wilkins, MR. Immonium ion scanning for the discovery of post-translational modifications and its application to histones. J Proteome Res. 2008; 7:263241. [PubMed: 18517236]

12. Fenaille F, Tabet JC, Guy Pa. Study of peptides containing modified lysine residues by tandem mass spectrometry: precursor ion scanning of hexanal-modified peptides. Rapid Commun Mass Spectrom. 2004; 18:67-76. [PubMed: 14689561]

13. Yalcin T, Csizmadia IG, Peterson MR, Harrison AG. The structure and fragmentation of B n ( $\mathrm{n} \geq 3)$ ions in peptide spectra. J Am Soc Mass Spectrom. 1996; 7:233-42. [PubMed: 24203294]

14. Tsunaka Y, Kajimura N, Tate S, Morikawa K. Alteration of the nucleosomal DNA path in the crystal structure of a human nucleosome core particle. Nucleic Acids Res. 2005; 33:3424-3434. [PubMed: 15951514]

15. Ozbal CC, Velic I, Soohoo CK, Skipper PL, Tannenbaum SR. Conservation of histone carcinogen adducts during replication: implications for long-term molecular dosimetry. Cancer Res. 1994; 54:5599-5601. [PubMed: 7923203]

16. Shechter D, Dormann HL, Allis CD, Hake SB. Extraction, purification and analysis of histones. Nat Protoc. 2007; 2:1445-1457. [PubMed: 17545981]

17. Boyne MT, Pesavento JJ, Mizzen CA, Kelleher NL. Precise characterization of human histories in the H2A gene family by top down mass spectrometry. J Proteome Res. 2006; 5:248-253. [PubMed: 16457589]

18. Sartoretto, JL., Kalwa, H., Romero, N., Michel, T. Methods Enzymol. 1. Elsevier Inc; 2013. In Vivo Imaging of Nitric Oxide and Hydrogen Peroxide in Cardiac Myocytes.

19. Niethammer P, Grabher C, Look aT, Mitchison TJ. A tissue-scale gradient of hydrogen peroxide mediates rapid wound detection in zebrafish. Nature. 2009; 459:996-999. [PubMed: 19494811] 
Relative abundance (\%)

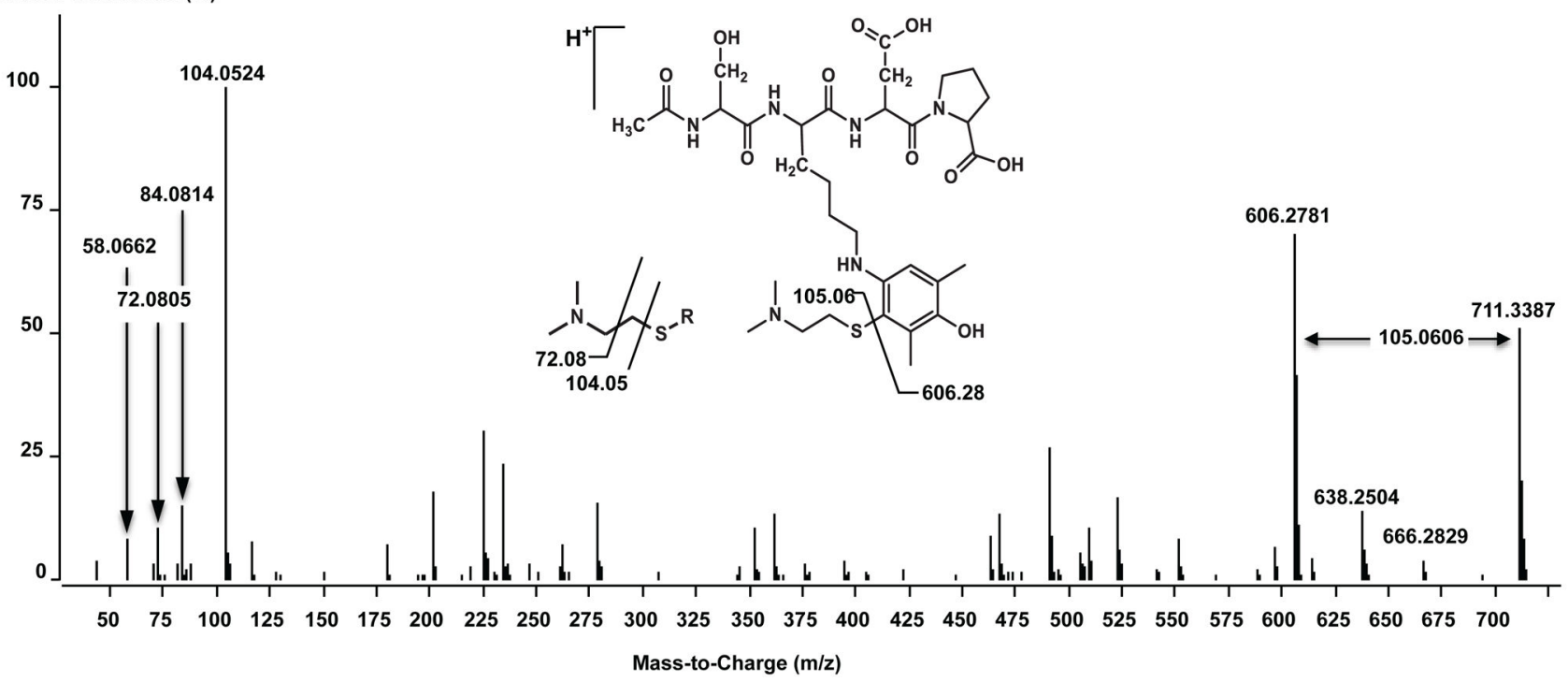

Figure 1.

High resolution CID MS of the DMET-derivatized model peptide containing a DMHPL residue. Ions at $m / z$ 104, 72, and 58 are characteristic of the DMET moiety and were used as trigger ions in targeted MS of unknowns. The ion at 606 is formed by loss of the elements of DMET as a neutral fragment. 


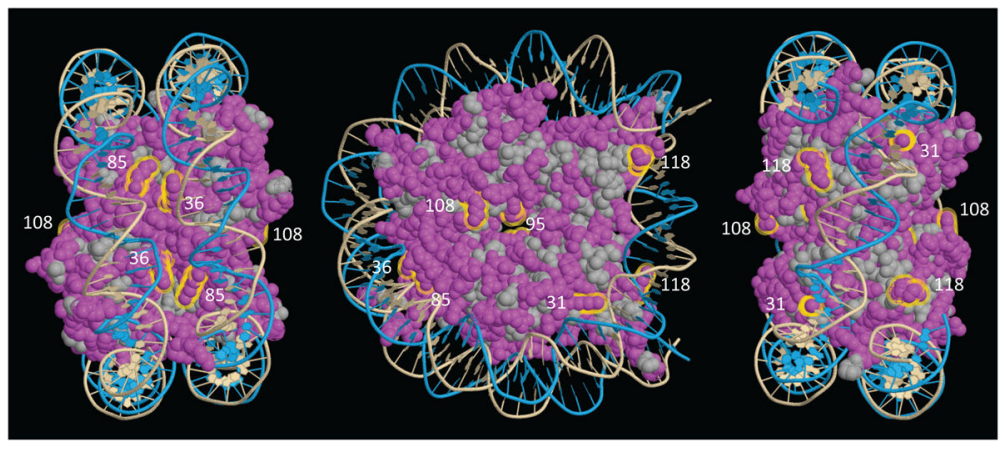

Figure 2.

Three views of the NCP with DNA showing locations of the lysine residues (outlined in yellow) that were identified as reacting with 3,5-DMAP. Images were created using FirstGlance in Jmol (http://bioinformatics.org/firstglance/fgij/). 


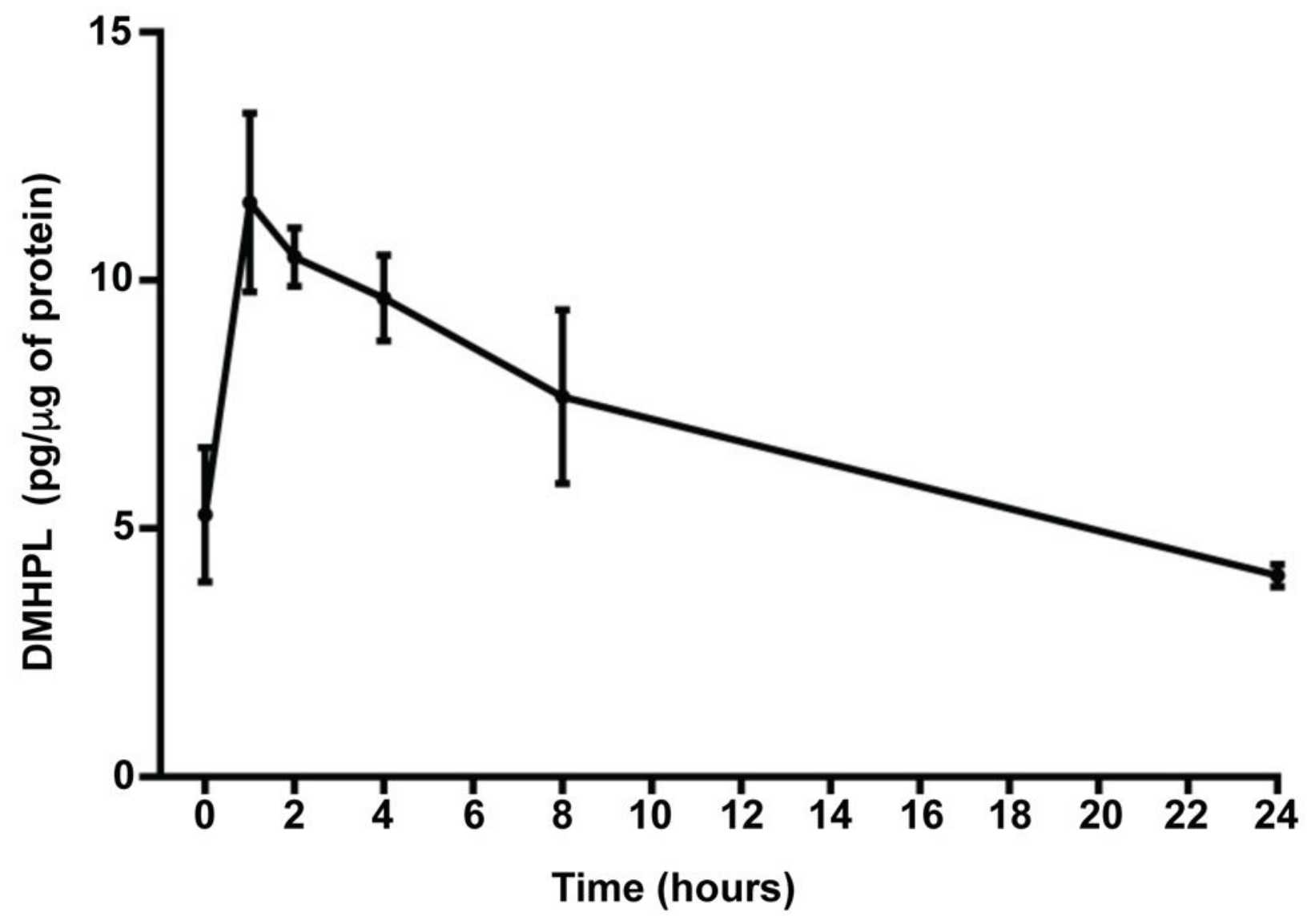

Figure 3.

Clearance of DMHPL from histones in CHO cells exposed to 3,5-DMAP. Each point represents the average of results from cell culture experiments conducted in triplicate. Error bars represent standard deviation. Limit of detection was approximately one $\mathrm{pg} / \mu \mathrm{g}$. 


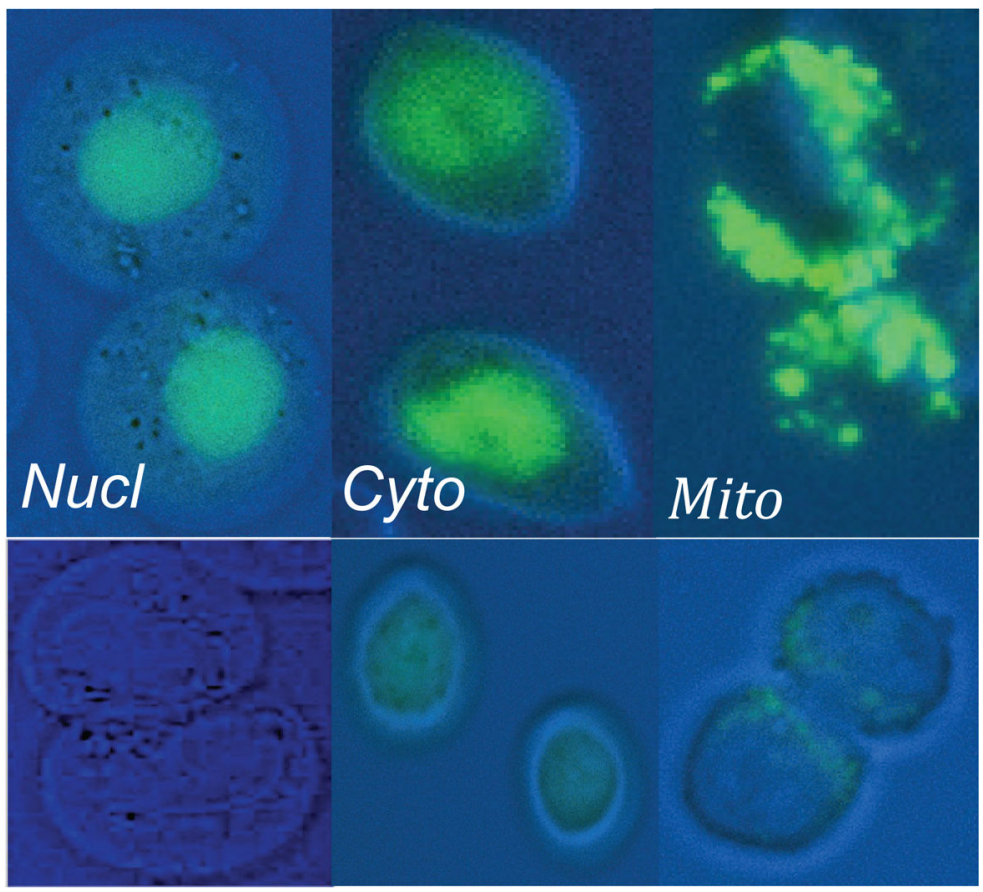

Figure 4.

CHO cells transfected with various HyPer constructs before (bottom) and after (top) exposure to $100 \mu \mathrm{M} \mathrm{H}_{2} \mathrm{O}_{2}$. 400x Magnification. 


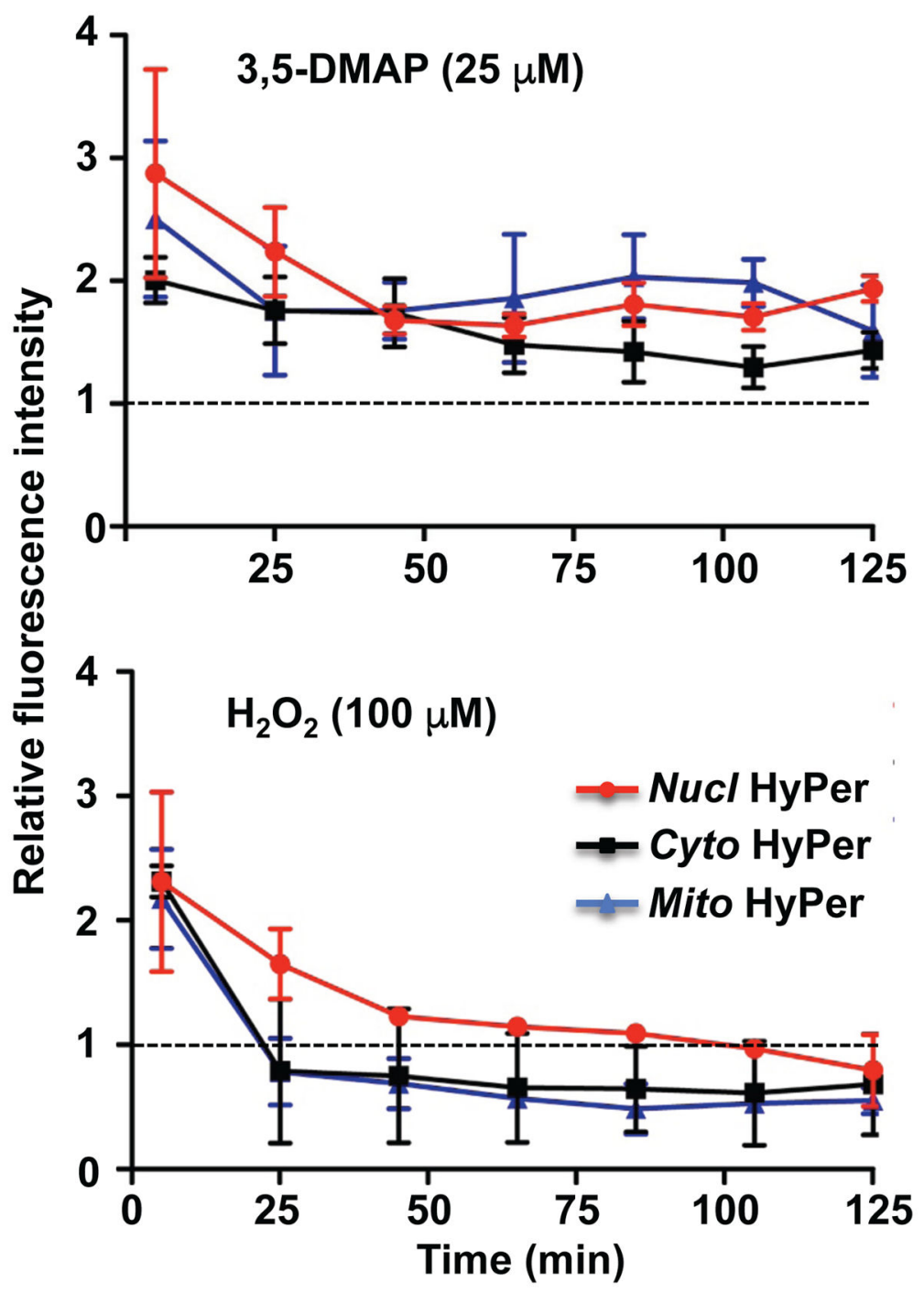

Figure 5.

Kinetics of immediate fluorescence response of HyPer-transfected cells following challenges with $100 \mu \mathrm{M} \mathrm{H}_{2} \mathrm{O}_{2}$ or $25 \mu \mathrm{M}$ 3,5-DMAP. Response is relative to control cells grown under identical conditions as represented by the line at $\mathrm{y}=1$. Cell culture experiments were conducted in triplicate and data are shown as mean \pm SD here and in figure 6. 


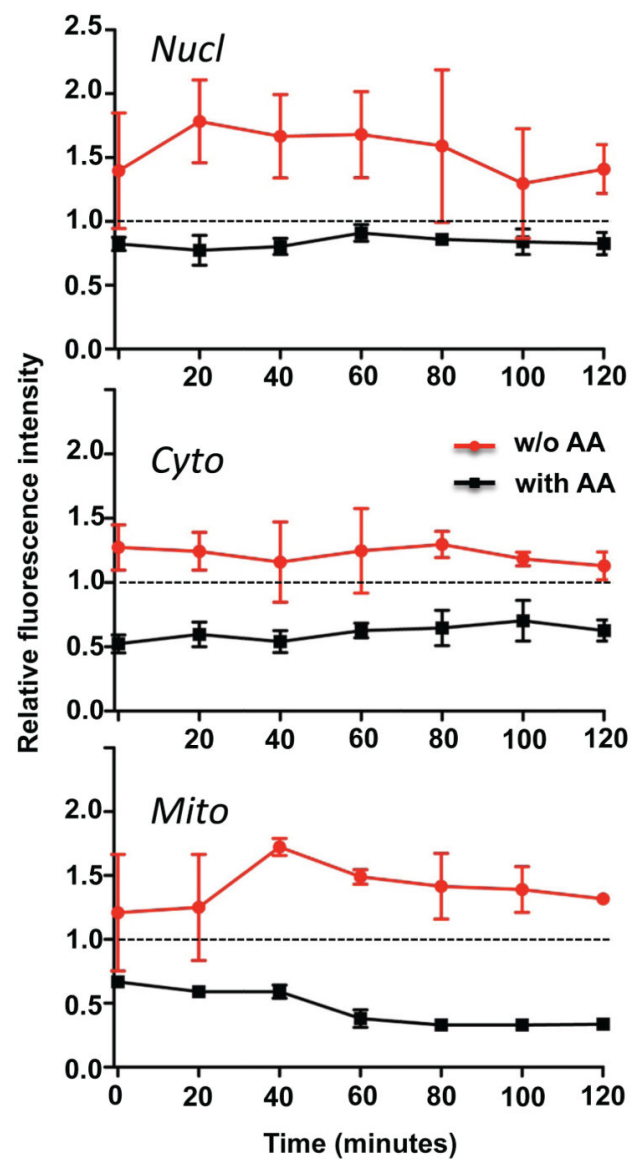

Figure 6.

Effect of ascorbate on the fluorescence response of cells exposed to $25 \mu \mathrm{M} 3,5$-DMAP for one hour followed by removal of the compound. Response is relative to control cells grown under identical conditions. 


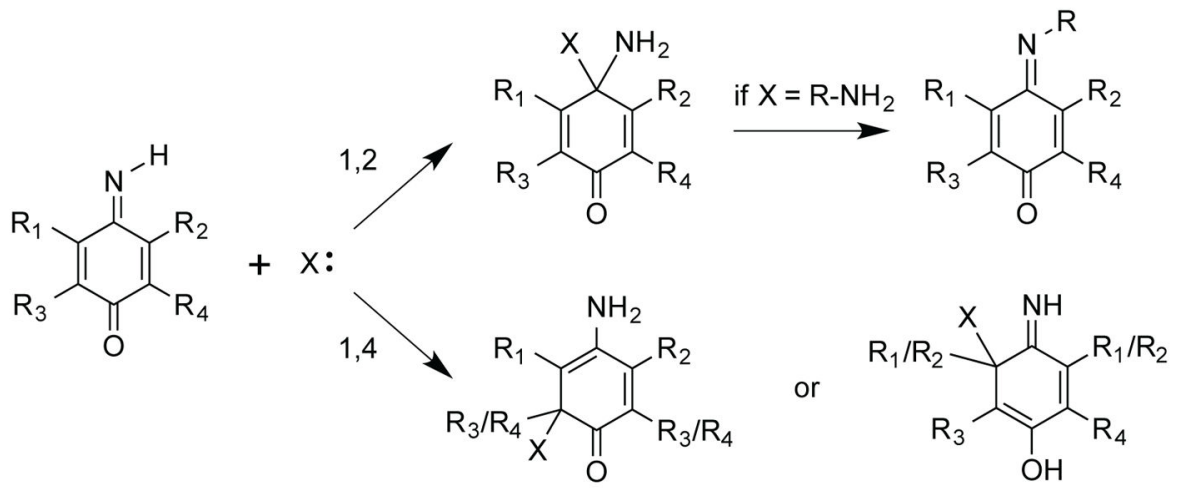

Scheme 1.

Pathways of nucleophilic attack by $\mathrm{X}$ on a quinone imine. Initial products of 1,4 addition may stabilize by aromatization if $\mathrm{R}_{\mathrm{n}}=\mathrm{H}$ at the site of attack. 

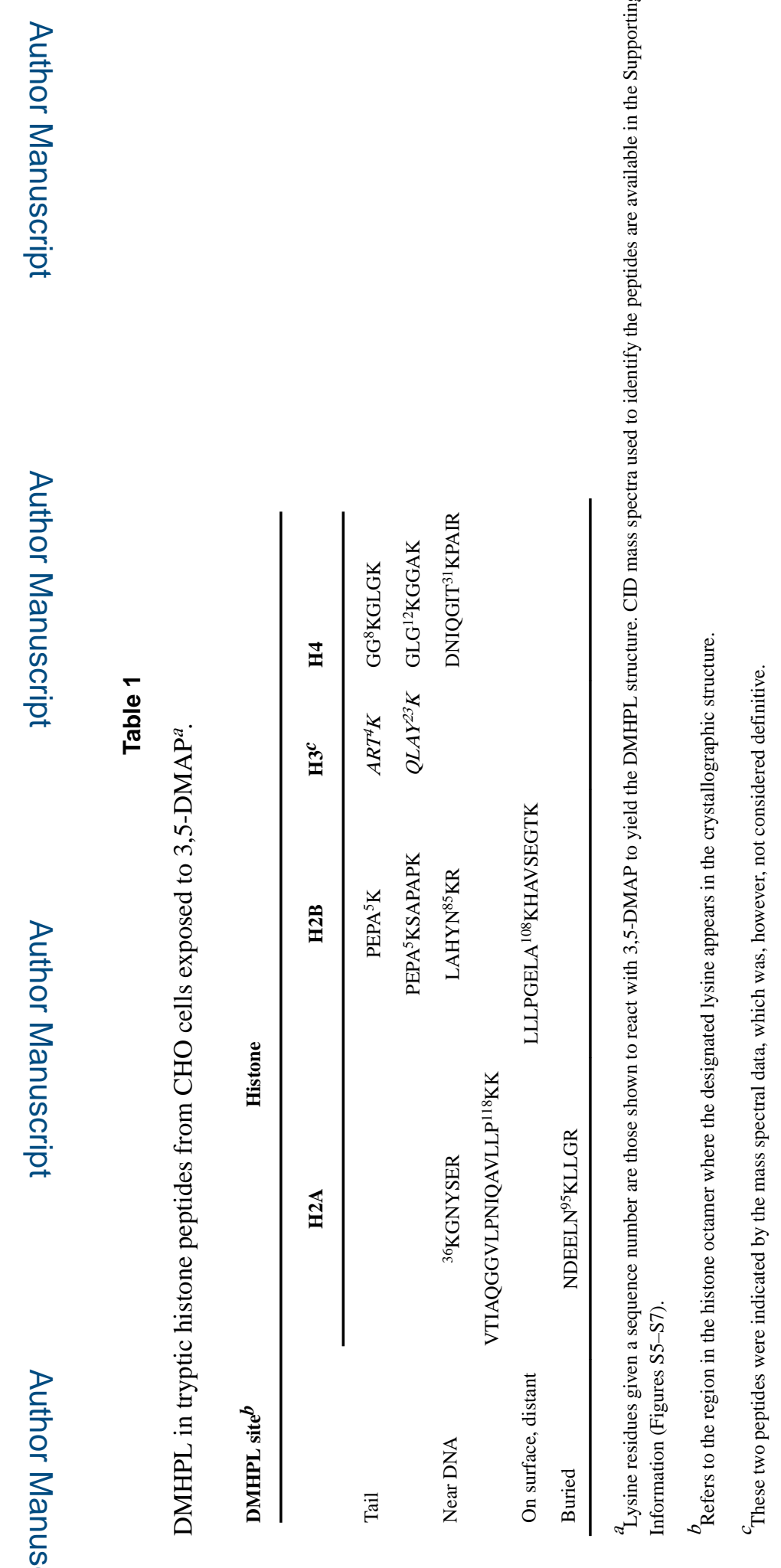

ACS Chem Biol. Author manuscript; available in PMC 2017 July 03. 